Review

\title{
Tissue Engineering of Corneal Endothelium
}

\section{Tatsuya Mimura $^{1, *}$, Seiichi Yokoo ${ }^{2}$ and Satoru Yamagami ${ }^{2}$}

1 Department of Ophthalmology, Tokyo Women's Medical University Medical Center East, 2-1-10 Nishiogu, Arakawa-ku, Tokyo 116-8567, Japan

2 Department of Ophthalmology, University of Tokyo Graduate School of Medicine, 7-3-1 Hongo, Bunkyo-ku, Tokyo 113-8655, Japan; E-Mails: syokoo-tky@umin.ac.jp (Se.Y.); syamagami-tky@umin.ac.jp (Sa.Y.)

* Author to whom correspondence should be addressed; E-Mail: mimurat-tky@umin.ac.jp; Tel.: +81-338-101-111; Fax: +81-338-940-282.

Received: 27 July 2012; in revised form: 12 September 2012 / Accepted: 17 September 2012 / Published: 17 October 2012

\begin{abstract}
Human corneal endothelial cells (HCECs) do not replicate after wounding. Therefore, corneal endothelial deficiency can result in irreversible corneal edema. Descemet stripping automated endothelial keratoplasty (DSAEK) allows selective replacement of the diseased corneal endothelium. However, DSAEK requires a donor cornea and the worldwide shortage of corneas limits its application. This review presents current knowledge on the tissue engineering of corneal endothelium using cultured HCECs. We also provide our recent work on tissue engineering for DSAEK grafts using cultured HCECs. We reconstructed DSAEK grafts by seeding cultured DiI-labelled HCECs on collagen sheets. Then HCEC sheets were transplanted onto the posterior stroma after descemetorhexis in the DSAEK group. Severe stromal edema was detected in the control group, but not in the DSAEK group throughout the observation period. Fluorescein microscopy one month after surgery showed numerous DiI-labelled cells on the posterior corneal surface in the DSAEK group. Frozen sections showed a monolayer of DiI-labelled cells on Descemet's membrane. These findings indicate that cultured adult HCECs, transplanted with DSAEK surgery, maintain corneal transparency after transplantation and suggest the feasibility of performing DSAEK with HCECs to treat endothelial dysfunction.
\end{abstract}


Keywords: review; corneal endothelium; descemet stripping automated endothelial keratoplasty; tissue engineering; transplantation

\section{Introduction}

The cornea is composed of a multilayered epithelium, Bowman's membrane, stroma, Descemet's membrane, and endothelium (Figure 1). Corneal endothelial cells (CECs) are firmly attached to the underlying Descemet's membrane. Corneal endothelial cells are believed to be of neural crest origin $[1,2]$ and form a monolayer of hexagonal cells. Transparency of the cornea is maintained by regulation of stromal hydration through the barrier and pump functions of the corneal endothelium. Human CECs (HCECs) normally have a limited proliferative capacity in vivo [3-7] because they are maintained in a Gl-phase arrested state [8,9]. Therefore, HCECs gradually decrease with age throughout life [10-12].

Figure 1. Anterior view of a human cornea and a diagram of the corneal epithelium, stroma and endothelium.
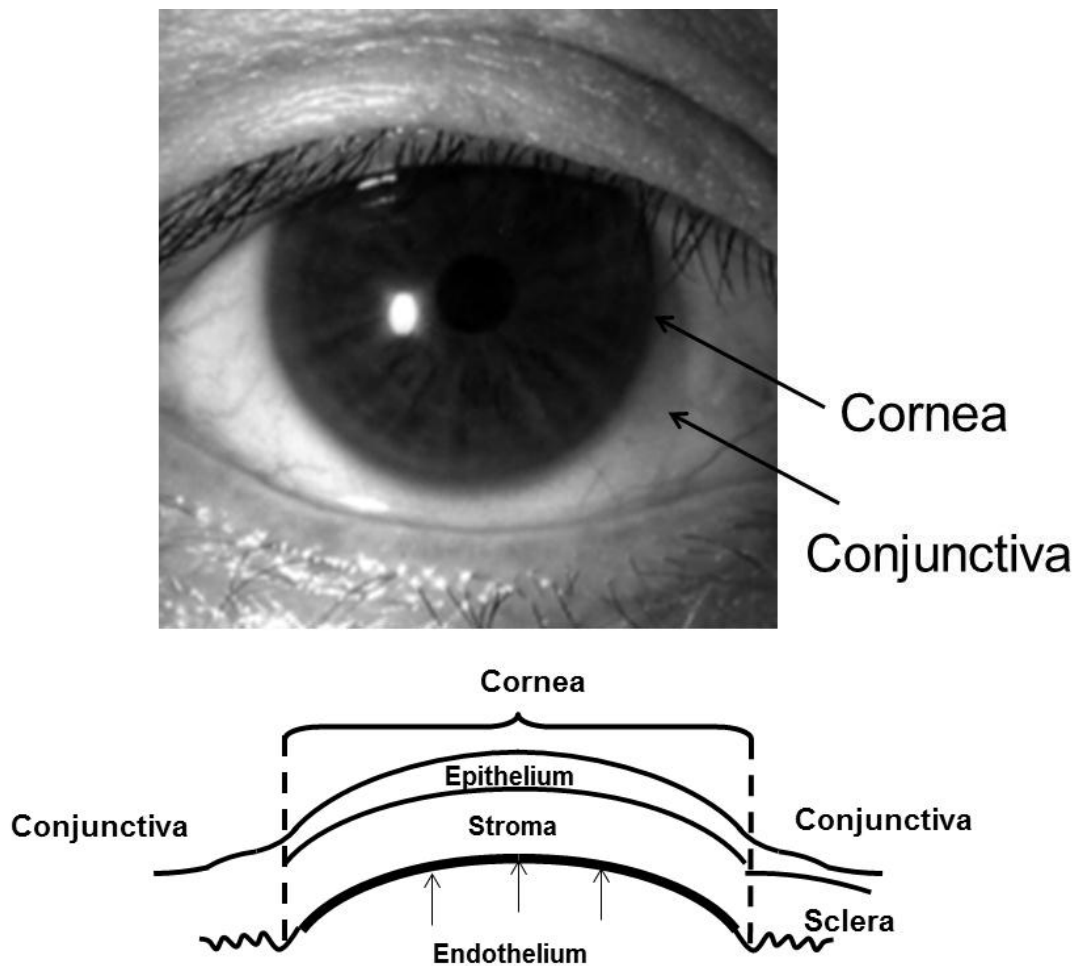

When primarily damaged, it is reasonable to replace only the corneal endothelium. Due to technical difficulties, treatment for corneal endothelial decompensation, such as pseudophakic or aphakic bullous keratopathy and Fuchs dystrophy, has been limited to penetrating keratoplasty (PKP). However, descemet stripping with automated endothelial keratoplasty (DSAEK) has recently become a standard procedure for corneal transplantation in patients with endothelial dysfunction [13-16]. This procedure improves postoperative visual function and reduces the risks associated with PKP, such as severe astigmatism and expulsive hemorrhage. However, DSAEK still requires a fresh donor cornea and endothelium, which are in limited supply. 
To overcome the problems of a donor cornea shortage, the application of CEC sheet transplantation using cultured HCECs has been attempted in experimental studies as a substitute for full-thickness corneal transplantation. Cultured HCECs derived from adult human donor corneas have been transplanted onto the denuded Descemet's membrane [17-27], collagen matrix [28], amniotic membrane [29], human corneal stromal discs [30,31], gelatin hydrogel discs [32,33], and chitosan-based membranes [34] ex vivo.

In this review, we will discuss the feasibility of DSAEK using cultured HCECs, as well as our recent work on the transplantation of cultured HCECs [28,30]. In the study described here, all procedures were performed in accordance with the ARVO Statement for the Use of Animals in Ophthalmic and Vision Research. Human donor corneas were handled according to the tenets of the Declaration of Helsinki of 1975 and its 1983 revision.

\section{Culture Technique of Human Corneal Endothelial Cells}

\subsection{Extracellular Matrix Substrates for Human Corneal Endothelial Cell Culture}

Several groups have established HCEC culture techniques [21,24,29,35,36]. It is reported that the attachment and growth of cultured HCECs can be promoted by artificial matrices, such as chondroitin sulfate and laminin [37], laminin-5 [38], extracellular matrix secreted by bovine corneal endothelial cells [36,39], and fibronectin plus type I collagen coating mix [40].

Recently, our laboratory investigated the expression of laminin-5 (LM5) and its receptors in HCECs and the influence of recombinant human LM5 on the adhesion, proliferation, and migration of cultured HCECs [38]. Human CECs expressed the LM5 receptor $\alpha 3 \beta 1$ integrin. Recombinant LM5 promoted adhesion, migration, and moderate proliferation of cultured HCECs. These results suggest that the functional system involving LM5 and the $\alpha 3 \beta 1$ receptor for LM5 may be a critical factor in promoting HCEC culture and may contribute to the practical use of tissue-engineered HCECs.

\subsection{Growth Factors and Cytokines for Human Corneal Endothelial Cell Culture}

In addition, various growth factors have been reported to influence the proliferation of cells cultured from human corneal endothelium, including fibroblast growth factor [21,24,35,37,41,42], epidermal growth factor [24,35,42,43], nerve growth factor [24], and endothelial cell growth supplement [35,39].

Recently, our laboratory developed a simple culture method for HCECs using L-ascorbic acid 2-phosphate (Asc-2P) [44]. In the study, the influence of Asc-2P on the growth of cultured HCECs was examined. Culturing with Asc-2P and basic fibroblast growth factor (bFGF) in atelocollagen promoted the proliferation of HCECs in both primary cultures and subcultures. During multiple passages, cultures without Asc-2P showed a decrease in growth and irregular cell morphology, whereas cultures with Asc-2P sustained cell growth and maintained the characteristic polygonal morphology. The levels of 8-hydroxy-2-deoxyguanosine in mitochondrial DNA showed a significant decrease when HCECs were subcultured with Asc-2P. These results suggest that the combination of Asc-2P and bFGF in atelocollagen allows successful culturing of HCECs. We speculated that Asc-2P extends the lifespan of cultured HCECs, partly due to its protection against oxidative DNA damage. Although many details of the mechanisms by which Asc-2P promotes cell growth remain unknown, 
the cell growth seems to be mediated through the scavenging of reactive oxygen species (ROS) and regulation of the synthesis of proteins related to cell growth. Joyce and associates demonstrated that treatment of cultured HCECs from young donors with increasing concentrations of hydrogen peroxide causes a dose-dependent increase in nuclear 8-hydroxy-2'-deoxyguanosine staining and a decrease in proliferative capacity similar to that observed in untreated HCECs from older donors [45]. They concluded that age-dependent and topographical decreases in proliferative capacity observed in HCECs resulted, at least in part, from nuclear oxidative DNA damage [45]. Conversely, hypoxia stimulates the growth of various cells [46,47], along with a decrease of intracellular ROS [48] and decreased expression of a negative cell cycle regulator, p21 Cip1 [49]. Taken together with our data indicating that Asc-2P potently diminished intracellular ROS generation, Asc-2P may promote HCEC growth by reducing intracellular oxidative stress.

Recently, Mergler and associates examined gene expression and function of transient receptor potential (TRP) channels of the vanilloid (V) isoform subfamily (i.e., TRPV1-3) in cultured HCECs to prove the role of temperature sensitive ion channels of cultured HCECs [50,51]. They demonstrated the expression of TRPV isotypes 1, 2 and 3 were detected by RT-PCR and protein expression of TRPV1 in situ was confirmed by immunostaining of corneoscleral remnants after keratoplasty. TRPV1-3 functional activity was evident based on capsaicin-induced $\mathrm{Ca}^{2+}$ transients and induction of these responses through rises in ambient temperature from $25{ }^{\circ} \mathrm{C}$ to over $40{ }^{\circ} \mathrm{C}$. The currents underlying $\mathrm{Ca}^{2+}$ transients were characterized with a novel high throughput patch-clamp system. The TRPV1 selective agonist, capsaicin $(10-20 \mu \mathrm{M})$ increased non-selective cation whole-cell currents resulting in calcium increases that were fully blocked by either the TRPV1 antagonist capsazepine or removal of extracellular calcium. Similarly, heating from room temperature to over $40{ }^{\circ} \mathrm{C}$ increased the same currents resulting in calcium increases that were significantly reduced by the TRP channel blockers lanthanum chloride ${ }^{3+}(100 \mu \mathrm{M})$ and ruthenium-red $(10 \mu \mathrm{M})$, respectively. Moreover, application of the TRPV channel opener 2-aminoethoxydiphenyl borate $(400 \mu \mathrm{M})$ led to a reversible increase in intracellular $\mathrm{Ca}^{2+}$ indicating putative TRPV1-3 channel activity. From these results, they concluded that TRPV activity modulation by temperature underlies essential homeostatic mechanisms contributing to the support of corneal endothelial function under different ambient conditions [50,51].

\subsection{Overview of Human Corneal Endothelial Cell Culture}

Currently, various culture media are used for cultivating HCECs, including Dulbecco's modified Eagle's medium (DMEM), Opti-MEM-I, DMEM/F12, and Ham's F12/M199, all of which have given satisfactory results. Peh and associates evaluated the effect of these four culture media in the isolation and propagation of HCECs [52]. They cultured HCECs in these four medium and found that HCECs isolated in all four media showed rapid attachment when cultured on FNC-coated dishes. However, HCECs cultured in DMEM and DMEM/F12 could not be propagated beyond the first and second passage, respectively. The HCECs cultured in Opti-MEM-I and Ham's F12/M199 were significantly more proliferative. However, the morphological characteristics of cultured HCECs were not maintained in either Opti-MEM-I or Ham's F12/M199 beyond the third passage. They concluded that the HCECs cultured in Opti-MEM-I and Ham's F12/M199 were significantly more proliferative and expressed markers characteristic of human corneal endothelium: $\mathrm{Na}+\mathrm{K}+/ \mathrm{ATP}$ ase and ZO-1 [52]. 
Furthermore, Engelmann's laboratory also recently evaluated the influence of five different organ culture media on corneal endothelial cell survival [53]. They cultured HCECs in five different media: HCEC growth medium (F99), standard MEM containing 2\% fetal calf serum (FCS), MEM containing $5 \%$ FCS, and humanized, endothelial serum-free medium (SFM) (with and without antibiotics). They found that the number of apoptotic cells in untreated control cultures was significantly higher in MEM compared with F99 and SFM. They concluded that HCECs cultured in MEM media seem susceptible to cell death in the absence of exogenous noxious stimuli, while HCEC cultured in SFM seem to be protected from cell death even when the apoptosis-inducer staurosporine is added [53]. They also speculated that the nutritive conditions in MEM therefore seem to be insufficient to sustain adequate compensatory mechanisms against oxidative cell stress.

\subsection{Human Corneal Endothelial Cell Culture in Our Laboratory}

Here, we describe a general culture method for HCEC that was performed in our laboratory. This method is based on both the published protocols of Joyce and our laboratory, with some modifications [24,36,40,54,55]. In our laboratory, all donor corneas were obtained from the Rocky Mountain Lion's Eye Bank. Briefly, Descemet's membrane with intact endothelium was carefully dissected. After centrifugation, the strips were incubated in $0.02 \%$ ethylenediamine tetraacetic acid disodium salt solution at $37{ }^{\circ} \mathrm{C}$ for $1 \mathrm{~h}$ to loosen intercellular junctions. Isolated cells were plated in 6-well tissue culture plates precoated with undiluted fibronectin plus type I collagen coating mix. The cultures were then maintained in Opti-MEM-I or low-glucose DMEM containing $8 \%$ fetal bovine serum and $2 \mathrm{ng} / \mathrm{mL}$ bFGF. Joyce's laboratory used a culture medium (OptiMEM-I) supplemented with $8 \%$ fetal bovine serum, $5 \mathrm{ng} / \mathrm{mL}$ epidermal growth factor (EGF), $20 \mathrm{ng} / \mathrm{mL}$ nerve growth factor (NGF), $100 \mu \mathrm{g} / \mathrm{mL}$ bovine pituitary extract, $20 \mu \mathrm{g} / \mathrm{mL}$ ascorbic acid, $200 \mathrm{mg} / \mathrm{mL}$ calcium chloride, and $0.08 \%$ chondroitin sulfate for HCEC culture [55]. The plates were then incubated at $37{ }^{\circ} \mathrm{C}$ in a humidified atmosphere with 5\% carbon dioxide. Once cells reached confluence, they were cultured in medium without supplements, such as FGF, EGF, NGF, or pituitary extract, for several days in order to stabilize the monolayer and optimally reflect its in vivo morphology [55]. After primary cultures reached confluence, cells were subcultured at a 1:4 ratio. With this method, primary cultured HCECs usually reached confluence in seven to ten days. Moreover, even the cultured HCECs at Passage 6 or 7 obtained from adult donor corneas by this procedure retained the HCEC-like morphology, exhibiting a regular hexagonal morphology in vivo (Figure 2).

Figure 2. Specular microscopy of a 62-year-old male patient (A) and semi-confluent; and (B) full-confluent; (C) P6 cultured human corneal endothelial cells (HCECs) derived from a 65-year-old donor. Confluent cells show the characteristic hexagonal shape of corneal endothelial cells. Scale bar $=100 \mu \mathrm{m}$.
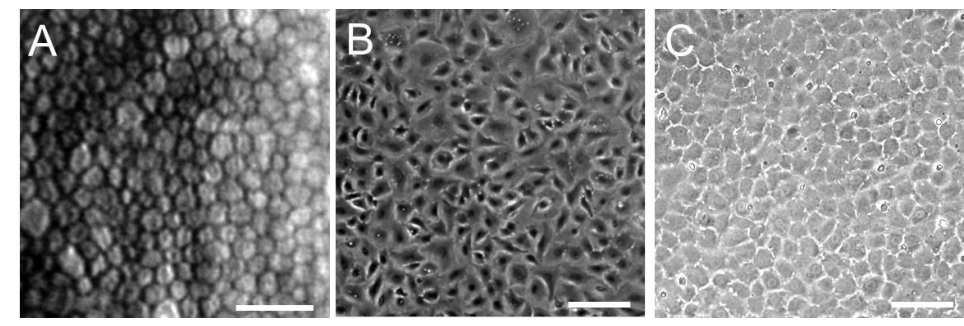
Recently, we succeeded in culturing and maintaining HCECs in a serum-free condition [38,44]. The use of serum-free medium avoids possible contamination with viruses, zoonosis from animals, and infection from bovine diseases by prions. Considering the clinical application of HCEC sheets, we must solve various problems, such as how to maintain product quality of culture medium during culturing HCECs and how to remove all animal-derived components from HCEC culture medium.

\section{Construction of a Human Corneal Endothelial Cell Sheet}

\subsection{Reconstruction of a Penetrating Keratoplasty Graft Using Cultured Human Corneal Endothelial Cells}

During the past few decades, several laboratories have reported carriers or tissue-engineering composites for use in the construction of HCEC sheets. In the initial studies of cultured CECs, full-thickness corneal transplantations were performed in animal models with reconstructed corneal grafts bearing cultured animal CECs seeded on cat [56], rabbit [57-59], bovine [58,60], or murine [61] Descemet's membranes or gelatin membranes $[62,63]$. Similar transplantation was performed in primates with cultured human neonatal and infant CECs [17-19].

The first attempt to construct CEC sheets using cultured CECs was performed by Gospodarowicz and Greenburg [56-58]. They seeded cultured bovine corneal endothelial cells onto bovine and rabbit corneas denuded of their endothelium. Subsequently, Engelmann's laboratory developed a technique to seed cultured HCECs onto human corneas denuded of their own endothelium [20,22,23]. In 2001, Joyce's laboratory reported a modified transplantation technique from an original method described by Gospodarowicz and Greenburg [24,56-58]. They seeded primary- or Passage 1-cultured HCECs onto the denuded Descemet's membrane of a donor cornea. The recipient cornea was incubated in organ culture for as long as two weeks. The mean endothelial cell density in the transplanted corneas was 1895 cells $/ \mathrm{mm}^{2}$ (range, $1503-2159$ cells $/ \mathrm{mm}^{2}$ ) [24].

Ishino and associates used amniotic membrane as a carrier for cultured HCEC transplantation [29]. They reported the density of the HCECs on the amniotic membrane was greater than $3000 \mathrm{cells} / \mathrm{mm}^{2}$. They transplanted the cultured HCEC sheets onto the rabbit cornea using PKP as follows. Circular HCEC sheets were placed on the endothelial side of an excised rabbit's cornea after the stripping of Descemet's membranes and these corneal buttons with circular HCEC sheets were transplanted by PKP. They reported that the transplanted cornea maintained corneal transparency for seven days after PKP using cultured HCEC sheets. We also succeeded in maintaining corneal transparency for six months in a rabbit model [25,26] and one month in a nude rat model [27] after PKP using the reconstructed full-thickness cornea with cultured HECEs.

\subsection{Construction of a Human Corneal Endothelial Cell Sheet for a Descemet Stripping Automated Endothelial Keratoplasty Graft}

The concept of these previous studies was based on the reconstruction of a full-thickness cornea using cultured HCECs because a full-thickness corneal transplantation technique had been mainly performed for CEC diseases such as Fuchs dystrophy and peudophakic or aphakic bullous keratopathy. However, this technique has frequent complications of high or irregular astigmatism, refractive error, and suture-related problems. Recently, DSAEK has become a standard procedure for corneal 
transplantation in patients with endothelial dysfunction [13-16]. This procedure improves postoperative visual function and reduces the risks associated with PKP, such as severe astigmatism and expulsive hemorrhage. In 2004, we had already established a method of transplanting only the cultured HCEC sheets before DSAEK was developed [28].

Here we introduce this new approach for treating CEC dysfunction using a cultured HCEC sheet for DSAEK. As the cell carrier, collagen sheets obtained from Nippi Research Institute of Biomatrix (Tokyo, Japan) were employed. These sheets were composed of a network of loosely cross-linked type I collagen fibers that had been treated with an alkaline solution, dried, and sterilized for $2 \mathrm{~h}$ under ultraviolet light $[64,65]$. Before use, the desiccated sheets were immersed in sterile saline for $10 \mathrm{~min}$. A $6.0-\mathrm{mm}$ trephine was used as the biopsy punch. Then $1.0 \times 10^{6} \mathrm{HCECs}$ in $300 \mu \mathrm{L}$ of culture medium were transferred to sheets in each well of 96-well plates. The plates were centrifuged at $1000 \mathrm{rpm}$ $(176 \times g)$ for $10 \mathrm{~min}$ to promote the attachment of cells to the sheets. After culturing for 2 days, nonadherent cells and debris were removed. Approximately 4000 100-mm culture dishes of confluent passage-5 HCECs can be produced from one donor cornea. And more than 10 HCEC sheets can be produced from one 100-mm dish. Therefore, we estimate that more than $1.0 \times 10^{3}$ HCEC sheets can be made using the passage-5 HCECs from one donor cornea. Additionally, similar morphology in sheen in 5th passage HCECs was observed in HCECs after being maintained in culture dishes for at least 7 passages. Therefore we speculate that this method still result in the same success of engineering HCEC using at least 7th passage HCECs.

After our initial report, we developed an HCEC sheet using a thin human corneal stromal disc as a carrier of cultured HCEC sheets in 2009 [30]. Additionally, we reconstructed the HCEC sheets by seeding the cultured HCECs on various carriers such as decellularized thin-layer pig corneal stroma and human amniotic membrane (data not shown). These newly developed HCEC sheets showed similar morphology to the collagen-based HCEC sheets.

Nishida's group reported a monolayer HCEC sheet that was cultured using novel temperature-responsive culture dishes onto which an ultrathin layer of temperature-responsive polymer, poly(N-isopropylacrylamide) (PIPAAm), is covalently grafted [66]. Nishida et al. commented that PIPAAm-grafted culture surfaces are slightly hydrophobic to facilitate cell adhesion under typical culture conditions at $37{ }^{\circ} \mathrm{C}$ because PIPAAm undergo a hydration phase transition across its lower critical solution temperature near $32{ }^{\circ} \mathrm{C}$ in water [66]. Because of the spontaneous and rapid hydration of the grafted PIPAAm, adherent cultured cells release spontaneously from these surfaces upon reducing culture temperature below the LCST without the need for proteolytic enzymes [66]. They had initially cultured HCECs on type IV collagen-coated dishes and seeded cultured HCECs onto the temperature-responsive culture dishes after several passages. The cells in their HCEC sheets showed primarily a hexagonal shape with numerous microvilli and cilia similar to the native corneal endothelium, by scanning electron microscopy. Lai and associates also cultured HCECs on a thermoresponsive type of PNIPAAm and seeded cultured HCECs onto gelatin hydrogel discs as a carrier of cultured HCEC sheets [32]. Choi and associates used decellularized thin-layer human corneal stroma as a carrier [31]. Liang and associates also developed a chitosan-based membrane made of hydroxyethyl chitosan, gelatin, and chondroitin sulfate as a new carrier of cultured HCEC sheets [34]. Additionally, Nishida and Tabata's group recently developed gelatin hydrogels as carrier 
sheets for the reconstruction of HCEC sheets [33]. These newly proposed materials are very attractive candidate materials for use in future HCEC tissue regeneration.

\subsection{Density of Cultured Human Corneal Endothelial Cells on Collagen Sheets}

We succeeded in achieving a mean endothelial cell density $>3000$ cells $/ \mathrm{mm}^{2}$ for HCECs cultured on collagen sheets by improving the cell seeding technique. Adhesion of the cells was promoted by centrifugation after seeding using the methods of Jamblatt [59] and Engelmann et al. [22,23] with modifications. Engelmann and associates recommended that each cell suspension be centrifuged at $33 \times \mathrm{g}$ for $5 \mathrm{~min}$ [22]. In our study, an HCEC suspension of $1.0 \times 10^{6}$ cells in $300 \mu \mathrm{L}$ culture medium was transferred to each sheet, and the sheet placed in individual wells of 96-well plates. The plates then were centrifuged at $1000 \mathrm{rpm}(176 \times \mathrm{g})$ for $10 \mathrm{~min}$ to enhance cell attachment to the sheets. Preoperative endothelial densities were around 1200 cells $/ \mathrm{mm}^{2}$ without centrifugation, but the density was increased to about 3500 cells $/ \mathrm{mm}^{2}$ by centrifuging the reconstructed corneal endothelial sheet. Application of fibronectin before cell seeding and a longer centrifugation time were found to prevent the detachment of HCECs from Descemet's membrane.

\subsection{Transport Activity of Human Corneal Endothelial Cell Sheets}

Corneal hydration and the consequential transparency depend primarily on sodium and bicarbonate ion transport, driven by the $\mathrm{Na}^{+} / \mathrm{K}^{+}$-adenosine triphosphatase $\left(\mathrm{Na}^{+} / \mathrm{K}^{+}\right.$-ATPase) pump [67-70] Therefore, the reconstructed HCEC sheets require transport activity to maintain corneal transparency after transplantation. We have examined the pump function in reconstructed HCEC sheets by electrophysiological measurements. The pump function of HCEC collagen sheets was measured in an Ussing chamber by the method reported previously with some modifications [71-73]. The donor corneas $(n=4)$, collagen sheets only $(n=4)$, and HCEC collagen sheets $(n=4)$ were mounted in the Ussing chamber. Corneas were incubated in Ringer solution containing $117.5 \mathrm{mM} \mathrm{NaCl}, 24 \mathrm{mM}$ $\mathrm{NaHCO}_{2}, 4 \mathrm{mM} \mathrm{KCl}, 1 \mathrm{mM} \mathrm{Na} \mathrm{HPO}_{4}, 1 \mathrm{mM} \mathrm{MgSO}_{4}, 4.45 \mathrm{mM}$ glucose, $1 \mathrm{mM}$ reduced glutathione and $2.54 \mathrm{mM} \mathrm{CaCl}_{2}$, and bubbled with a $5 \% \mathrm{CO}_{2}-7 \% \mathrm{O}_{2}, 88 \% \mathrm{~N}_{2}$ gas mixture to $\mathrm{pH} 7.38$. After steady state levels of the potential difference and short circuit current were reached, $0.1 \mathrm{mM}$ ouabain, an $\mathrm{Na}^{+}, \mathrm{K}^{+}$-ATPase inhibitor, was added to the chamber and the potential difference and short circuit current were redetermined. The mean potential difference of the HCEC collagen sheets was $85 \%$ at $1 \mathrm{~min}, 80 \%$ at $5 \mathrm{~min}$ and $95 \%$ at $10 \mathrm{~min}$ of that for human donor corneas (Figure $3 \mathrm{~A}$ ). The average short circuit current of the HCEC collagen sheets was $76 \%$ at $1 \mathrm{~min}, 78 \%$ at $5 \mathrm{~min}$ and $82 \%$ at $10 \mathrm{~min}$ of that for human donor corneas denuded of epithelium. The potential difference and short circuit currents of the collagens sheets and human donor corneas denuded of epithelium and endothelium were $0 \mathrm{mV}$ and $0 \mathrm{~A}$ at each time of assessment (Figures $3 \mathrm{~A}$ and $3 \mathrm{~B}$ ). After the $\mathrm{Na}^{+}, \mathrm{K}^{+}$-ATPase inhibitor ouabain was added to the chambers, the potential difference and short circuit currents reached $0 \mathrm{mV}$ for all test samples within $5 \mathrm{~min}$. These results indicate that CEC pump function, which mainly depends on $\mathrm{Na}^{+}, \mathrm{K}^{+}$-ATPase, was satisfactory with our HCEC sheets. 
Figure 3. The pump functions in reconstructed HCEC sheets (arranged from reference [28] with permission). Potential difference (A) and short circuit current; (B) of human donor corneas $(n=4)$, cultured HCEC collagen sheets $(n=4)$, and bare collagen sheets $(n=4)$ are measured by an Ussing chamber. (A) The average potential difference for HCEC sheets is $80 \%-95 \%$ of that for human donor corneas denuded of epithelium. Addition of ouabain (an $\mathrm{Na}^{+}-\mathrm{K}^{+}$ATPase inhibitor) causes the potential difference to become $0 \mathrm{mV}$ in all samples tested; (B) The average short circuit current for HCEC sheets is $76 \%-82 \%$ of that for human donor corneas denuded of epithelium. Addition of ouabain causes the short circuit current to become $0 \mu \mathrm{A}$ in all samples tested. The data were analyzed using one-way analysis of variance and the Scheffe's multiple comparison test.

A
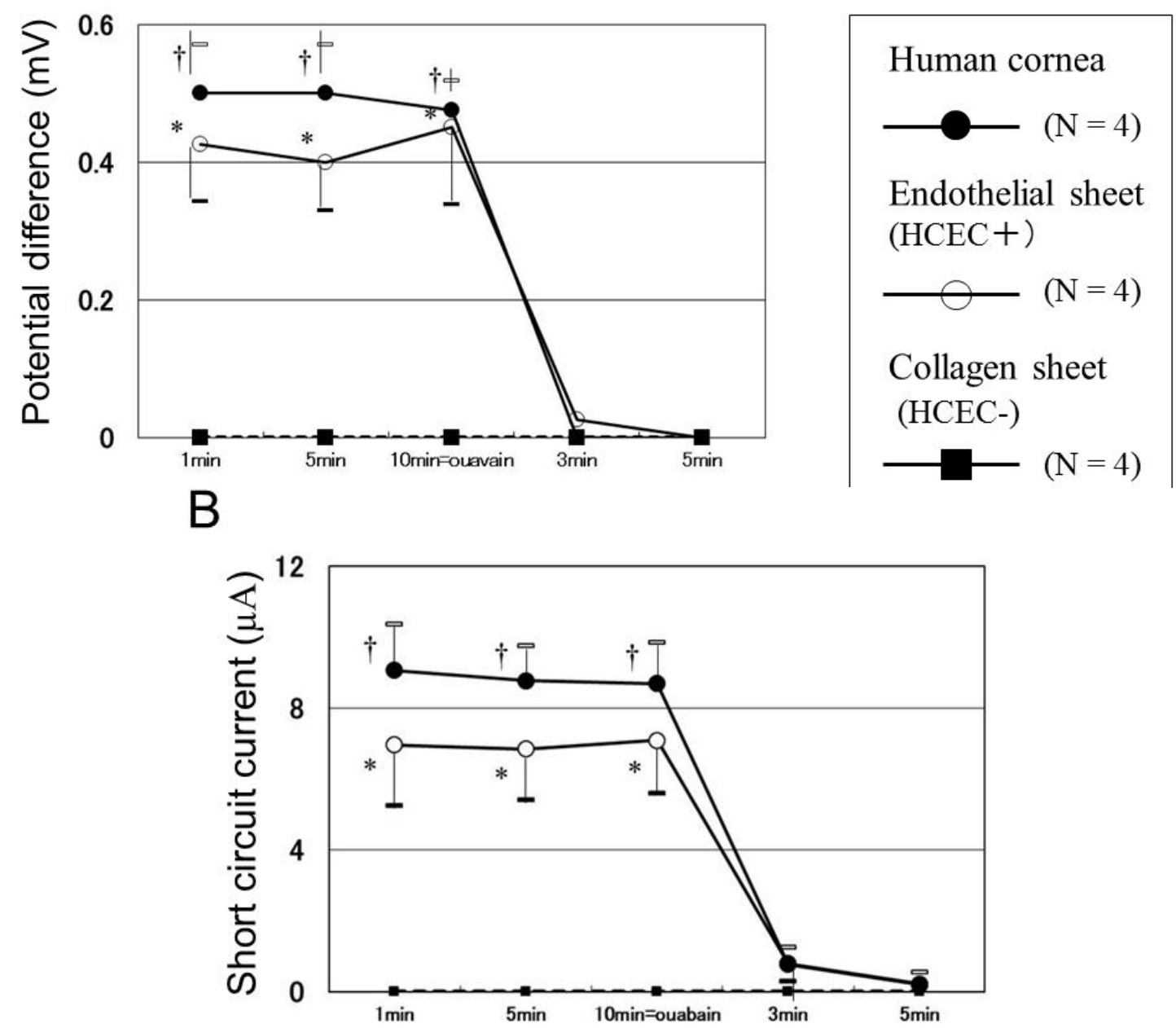

Notes: $* \mathrm{p}<0.001$, HCEC sheet $v s$. collagen sheet; $\uparrow \mathrm{p}<0.001$, human donor cornea $v$ s. collagen sheet; Closed circles indicate human donor corneas denuded of epithelium $(n=4)$; open circles indicate HCEC sheets $(n=4)$; squares indicate bare collagen sheets $(n=4)$. Data are the mean \pm SD. 


\section{Transplantation of Descemet Stripping Automated Endothelial Keratoplasty Grafts Using Cultured Human Corneal Endothelial Cells}

\subsection{Transplantation of Human Corneal Endothelial Cell Sheets Using Collagen as a Carrier in a Rabbit Model}

We described the first application of cultured HCEC sheets for DSAEK grafts in 2004 [28]. In the study, we used a collagen sheet as a carrier for cultured HCEC transplantation. In our second study, DSAEK grafts were produced by seeding cultured HCEC suspensions onto thin-layer human corneal stromal discs [30]. These DSAEK grafts were transplanted into rabbit corneas and HCECs seeded on DSAEK grafts succeeded in maintaining a morphology similar to HCECs in vivo and contributed to reduce corneal edema in an animal model.

\subsection{Other Attempts to Transplant Cultured Corneal Endothelial Cell Sheets in Animal Models}

Several other research groups also reported developing DSAEK grafts using cultured CECs (Table 1). Lai and associated transplanted HCEC sheets cultured on PNIPAAm and gelatin-based material into rabbit eyes and found that corneal transparency was restored within two postoperative weeks [32]. Koizumi and associates reconstructed monkey CEC sheets by the cultivation of monkey CECs on collagen type I carriers for four weeks [74,75]. They transplanted the reconstructed monkey CEC sheets into monkey eyes using the DSAEK technique. The transplanted sheets were detached from the host corneas one week after grafting, but the corneas recovered their clarity in the surgical eyes that received cultivated monkey CEC sheet transplants six months after transplantation.

Table 1. Summary of transplantation technique of cultured corneal endothelial cell sheets in animal models.

\begin{tabular}{|c|c|c|c|c|c|}
\hline Author & $\begin{array}{c}\text { Species of } \\
\text { cultured CEC }\end{array}$ & Cell carrier & $\begin{array}{c}\text { Host } \\
\text { animal } \\
\end{array}$ & $\begin{array}{c}\text { Transplantation } \\
\text { technique }\end{array}$ & Journal (Year) \\
\hline Mimura & Human & Collagen & Rabbit & DSAEK & $\begin{array}{l}\text { Invest Ophthalmol Vis } \\
\text { Sci (2004) }\end{array}$ \\
\hline Ishino & Human & $\begin{array}{l}\text { Amniotic } \\
\text { membrane }\end{array}$ & Rabbit & PKP & $\begin{array}{l}\text { Invest Ophthalmol Vis } \\
\text { Sci (2004) }\end{array}$ \\
\hline Sumide & Human & PNIPAAm & Rabbit & PKP & FASEB J (2006) \\
\hline Lai & Human & $\begin{array}{l}\text { PNIPAAm and } \\
\text { gelatin }\end{array}$ & Rabbit & DSAEK & $\begin{array}{l}\text { Transplantation } \\
\text { (2007) }\end{array}$ \\
\hline Koizumi & Monkey & Collagen & Monkey & DSAEK & $\begin{array}{l}\text { Invest Ophthalmol Vis } \\
\text { Sci (2007) }\end{array}$ \\
\hline Honda & Human & $\begin{array}{c}\text { Thin human } \\
\text { corneal stromal } \\
\text { disc }\end{array}$ & Rabbit & DSAEK & $\begin{array}{l}\text { Arch Ophthalmol } \\
\text { (2009) }\end{array}$ \\
\hline
\end{tabular}

Notes: CEC, Corneal Endothelial Cell; PKP, Penetrating Keratoplasty; DSAEK, Descemet Stripping Automated Endothelial Keratoplasty. 


\subsection{Transplantation Technique of Human Corneal Endothelial Cell Sheets with Descemet Stripping} Automated Endothelial Keratoplasty

Here, we shall introduce our experimental DSAEK model using cultured HCEC sheets (Figure 4) and then describe empirical observations after the transplantation of a DSAEK graft. In our first transplantation of a DSAEK graft using culture HCECs, a 6-mm sclerocorneal incision centered at 12 o'clock was made with a slit knife, a circular descemetorhexis $(6.0-\mathrm{mm}$ in diameter) was created in the center of the rabbit cornea with a 30-gauge needle, and Descemet's membrane was removed from the anterior chamber. A circular HCEC sheet (with the HCEC side up) was brought into the anterior chamber and then was fixed to the posterior stroma that had been stripped of Descemet's membrane. If the sheet was difficult to attach, an air bubble was injected into the anterior chamber. The sclerocorneal wound was closed with two or three interrupted sutures of 10-0 nylon. This transplantation technique is almost the same as that in the clinically performed DSAEK procedure. The rabbits were divided into either the DSAEK group (rabbits with peeling of Descemet's membrane and transplantation of an HCEC sheet) or the control group (rabbits with peeling of Descemet's membrane only). Each group comprised of four rabbits (four eyes). No immunosuppressive agents were administered either topically or systemically.

Figure 4. Procedure for HCEC sheet transplantation. (A) HCEC collagen sheet on a silicon plate; (B) A 6-mm sclerocorneal incision centered at 12 o'clock is made with a slit-knife; (C) A 6.0-mm diameter circular Descemetorhexis was performed with a 30-gauge needle and Descemet's membrane was removed from the anterior chamber; (D,E,F): (D) The HCEC sheet was inserted into the anterior chamber using the forceps; or (E) a foldable silicone plate; and (F) attached to the posterior stroma.
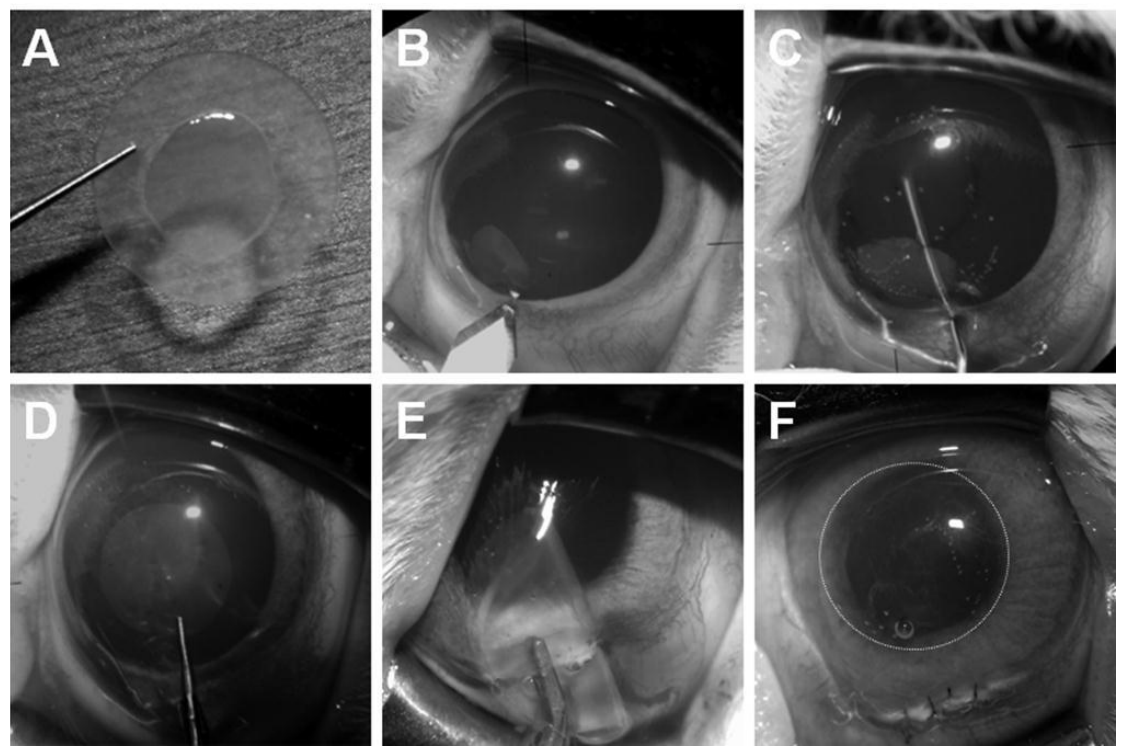

\subsection{Observation after Transplantation}

Corneal edema decreased much earlier after HCEC sheet transplantation in the DSAEK group than in the control group. In the control group, mean corneal thickness remained at approximately $1000 \mu \mathrm{m}$ 
throughout the 28-day observation period. In contrast, corneal edema decreased rapidly in the DSAEK group and the cornea was significantly thinner than in the control group at $1(P<0.05$, unpaired t-test), 3, 7, 14, 21 and 28 days $(P<0.001$, unpaired t-test) after surgery. Figure 5 shows representative anterior segment photographs from each group. The cornea is opaque with severe stromal edema in the control group, while the cornea transplanted with a cultured HCEC sheet is clear and has no stromal edema on Day 28 in the DSAEK group (Figure 5). In the DSAEK group, grafts remained transparent for one month after surgery and the corneas with HCEC sheets were significantly thinner than the corneas of the control group. These results suggest the feasibility of performing corneal reconstruction by using HCECs cultured from adult donor corneas.

Figure 5. Central corneal thickness (A) and anterior segment photographs $(\mathbf{B}, \mathbf{C})$ after transplantation of a DSAEK graft reconstructed with collagen and cultured HCECs [28]. The DSAEK graft using cultured HCECs and collagen (DSAEK group) or a bare collagen sheet (control group) are transplanted into rabbit corneas after stripping of the Descemet membrane. In the control group (open circles), the mean corneal thickness remains at around $1000 \mathrm{~m}$ for 28 days. In contrast, the mean corneal thickness gradually decreases in the DSAEK group (closed circles) and becomes significantly less than in the control group. There are significant differences of corneal thickness between the DSAEK and control groups on Days 1, 3, 7, 14, 21 and 28 using an unpaired t-test. (B) Representative anterior segment photographs obtained with a slit-lamp microscope at 28 days after surgery show a thin cornea without stromal edema in the DSAEK group; $(\mathbf{C})$ while severe corneal edema is observed in the control group.
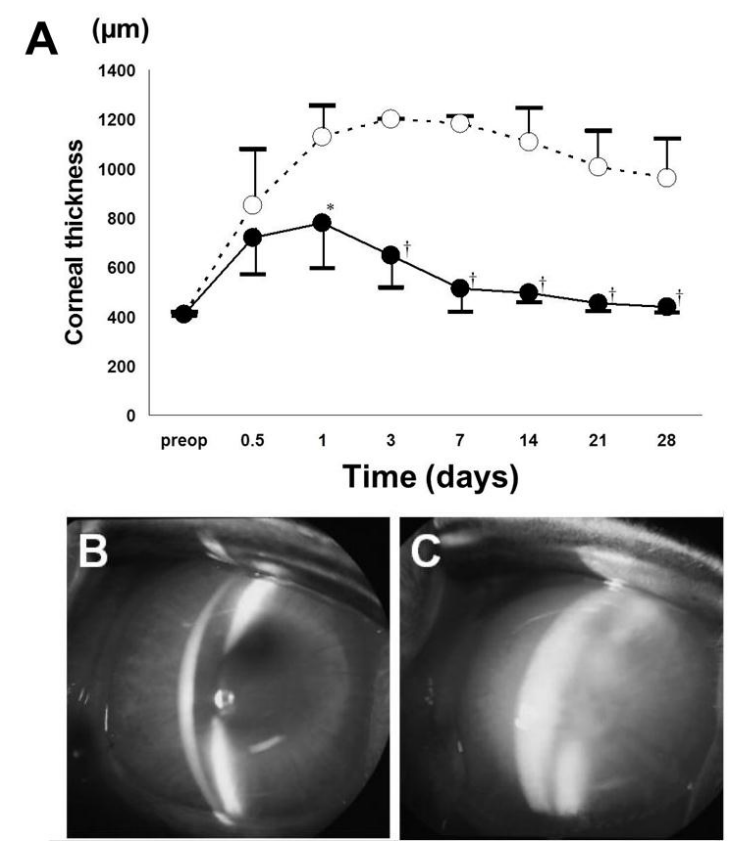

Notes: $* \mathrm{p}<0.05, \dagger \mathrm{p}<0.01$

\subsection{Histologic Examination}

Fluorescence microscopy of whole mounted corneas showed DiI-positive cells localized on the transplanted collagen sheet and a clear margin of the sheet at 28 days after transplantation. The HCECs 
on the collagen sheets had a fairly regular morphology with well-defined boundaries. Most cells on the collagen sheets transplanted to the posterior surface of the cornea were DiI-positive in the DSAEK group analyses; details can be found in the original article [28]. Because endocytosed DiI cannot be transferred to adjacent cells [76], it is probable that the cultured HCECs remained on the sheet. The endothelial cell density of the four grafts in the DSAEK group was around 2500 cells $/ \mathrm{mm}^{2}$ at 28 days after surgery, whereas the preoperative endothelial density was around 3500 cells $/ \mathrm{mm}^{2}$. In the control group, no CECs were detected on the stroma at the site of the descemetorhexis.

Hematoxylin-eosin-stained sections obtained 28 days after transplantation are shown in Figure 6. There is edema and diffuse cellular infiltration of the stroma in the control group (Figure 6A). Fibrous tissue and fibroblast-like cells were observed in the posterior stroma of the control group (Figure 6B). In contrast, there was no edema of the transplanted HCEC collagen sheets in the DSAEK group (Figure 6C,D).

Figure 6. Histological examination of the cornea at 28 days after surgery. $(\mathbf{A}, \mathbf{B})$ In the control group, HCECs and Descemet's membrane are absent. Severe stromal edema and diffuse cell infiltration are observed; (C,D) Hematoxylin-eosin staining shows a collagen sheet with HCECs on the posterior surface of the cornea and no stromal edema in the DSAEK group. Fibroblast-like cells are detected in the posterior corneal stroma attached to the collagen sheet.

A

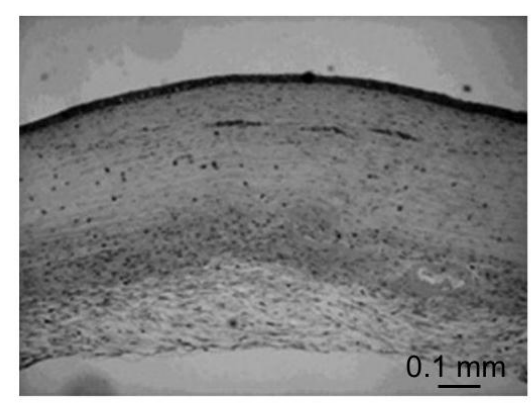

B Endothelium

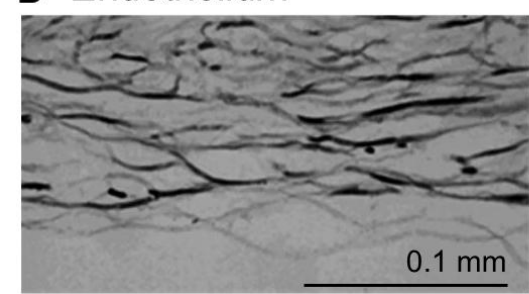

C

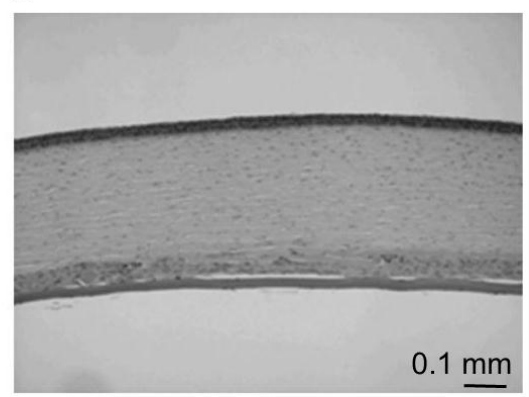

D

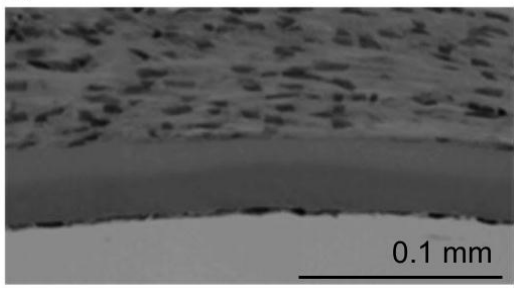

The study of the transplantation of DSAEK graft using the thin-layer human corneal stromal discs as a carrier for cultured HCEC transplantation showed almost the same results that were seen in this study [30]. Furthermore, we transplanted the bioengineered DSAEK graft using cultured HCECs and human amniotic membrane into rabbits' cornea and this DSAEK model using an amniotic membrane as a carrier also showed rapid recovery of corneal edema without possible side effects such as intraocular pressure increase and graft rejection (data not shown). In these various DSAEK models using cultured HCECs, HCEC grafts remained transparent for one month after surgery and the HCEC sheets were significantly thinner than the corneas of the untransplanted control group. These results suggest the feasibility of performing corneal reconstruction by using HCECs cultured from adult donor corneas. 


\section{Conclusion}

New techniques that can replace full-thickness corneal transplantation have been tried both clinically and experimentally. DSAEK surgery has rapidly replaced conventional PKP as the preferred procedure for the treatment of endothelial disorders. This paper has highlighted some of the latest experimental innovations in DSAEK surgery using cultured HCEC sheets to overcome donor organ shortage. The novel techniques presented here are good candidates for future treatments of CEC dysfunction. Autologous CEC transplantation is undoubtedly an ideal strategy to completely negate the possibility of rejection. Because CECs from the peripheral cornea contain a higher density of precursors than CECs from the central cornea in rabbits [77] and humans [78], cultures of peripheral cells obtained by resecting a small piece of Descemet's membrane may eventually allow HCEC sheet transplantation for unilateral bullous keratopathy. Cultured HCECs should become a powerful tool for cell or tissue repair and regeneration of corneal endothelium.

\section{Acknowledgements}

The authors wish to thank the numerous individuals that have been part of our laboratory over the last 10 years on whose work this review article was based. These include Masahiro Yamaguchi, Norihiko Honda, Nobuyuki Shima and Tomohiko Usui. We would like to express our sincere thanks to all members of Joyce's laboratory, including Deshea L. Harris, Kikuko Enomoto, Kenji Konomi, Yutaka Ishino and Cheng Zhu. Lastly, the authors are most grateful to Shiro Amano of Tokyo University and Nancy C. Joyce of Harvard Medical School for many helpful discussions and their encouragement to study corneal endothelium.

\section{Financial Support}

No author has a financial or proprietary interest in any material or method mentioned.

\section{References}

1. Johnston, M.C.; Noden, D.M.; Hazelton, R.D.; Coulombre, J.L.; Coulombre, A.J. Origins of avian ocular and periocular tissues. Exp. Eye Res. 1979, 29, 27-43.

2. Bahn, C.F.; Falls, H.F.; Varley, G.A.; Meyer, R.F.; Edelhauser, H.F.; Bourne, W.M. Classification of corneal endothelial disorders based on neural crest origin. Ophthalmology 1984, 91, 558-563.

3. Wilson, S.E.; Lloyd, S.A.; He, Y.G.; McCash, C.S. Extended life of human corneal endothelial cells transfected with the sv40 large t antigen. Invest. Ophthalmol. Vis. Sci. 1993, 34, 2112-2123.

4. Wilson, S.E.; Weng, J.; Blair, S.; He, Y.G.; Lloyd, S. Expression of E6/E7 or SV40 large T antigen-coding oncogenes in human corneal endothelial cells indicates regulated high-proliferative capacity. Invest. Ophthalmol. Vis. Sci. 1995, 36, 32-40.

5. Egan, C.A.; Savre-Train, I.; Shay, J.W.; Wilson, S.E.; Bourne, W.M. Analysis of telomere lengths in human corneal endothelial cells from donors of different ages. Invest. Ophthalmol. Vis. Sci. 1998, 39, 648-653.

6. Senoo, T.; Joyce, N.C. Cell cycle kinetics in corneal endothelium from old and young donors. Invest. Ophthalmol. Vis. Sci. 2000, 41, 660-667. 
7. Senoo, T.; Obara, Y.; Joyce, N.C. EDTA: A promoter of proliferation in human corneal endothelium. Invest. Ophthalmol. Vis. Sci. 2000, 41, 2930-2935.

8. Joyce, N.C.; Meklir, B.; Joyce, S.J.; Zieske, J.D. Cell cycle protein expression and proliferative status in human corneal cells. Invest. Ophthalmol. Vis. Sci. 1996, 37, 645-655.

9. Joyce, N.C.; Navon, S.E.; Roy, S.; Zieske, J.D. Expression of cell cycle-associated proteins in human and rabbit corneal endothelium in situ. Invest. Ophthalmol. Vis. Sci. 1996, 37, 1566-1575.

10. Murphy, C.; Alvarado, J.; Juster, R.; Maglio, M. Prenatal and postnatal cellularity of the human corneal endothelium. A quantitative histologic study. Invest. Ophthalmol. Vis. Sci. 1984, 25, 312-322.

11. Bourne, W.M.; Nelson, L.R.; Hodge, D.O. Central corneal endothelial cell changes over a ten-year period. Invest. Ophthalmol. Vis. Sci. 1997, 38, 779-782.

12. Hollingsworth, J.; Perez-Gomez, I.; Mutalib, H.A.; Efron, N. A population study of the normal cornea using an in vivo, slit-scanning confocal microscope. Optom. Vis. Sci. 2001, 78, 706-711.

13. Gorovoy, M.S. Descemet-stripping automated endothelial keratoplasty. Cornea 2006, 25, 886-889.

14. Koenig, S.B.; Covert, D.J. Early results of small-incision descemet's stripping and automated endothelial keratoplasty. Ophthalmology 2007, 114, 221-226.

15. Price, M.O.; Baig, K.M.; Brubaker, J.W.; Price, F.W., Jr. Randomized, prospective comparison of precut $v s$. surgeon-dissected grafts for descemet stripping automated endothelial keratoplasty. Am. J. Ophthalmol. 2008, 146, 36-41.

16. Terry, M.A.; Shamie, N.; Chen, E.S.; Hoar, K.L.; Friend, D.J. Endothelial keratoplasty a simplified technique to minimize graft dislocation, iatrogenic graft failure, and pupillary block. Ophthalmology 2008, 115, 1179-1186.

17. Insler, M.S.; Lopez, J.G. Transplantation of cultured human neonatal corneal endothelium. Curr. Eye Res. 1986, 5, 967-972.

18. Insler, M.S.; Lopez, J.G. Extended incubation times improve corneal endothelial cell transplantation success. Invest. Ophthalmol. Vis. Sci. 1991, 32, 1828-1836.

19. Insler, M.S.; Lopez, J.G. Heterologous transplantation versus enhancement of human corneal endothelium. Cornea 1991, 10, 136-148.

20. Aboalchamat, B.; Engelmann, K.; Bohnke, M.; Eggli, P.; Bednarz, J. Morphological and functional analysis of immortalized human corneal endothelial cells after transplantation. Exp. Eye Res. 1999, 69, 547-553.

21. Engelmann, K.; Friedl, P. Optimization of culture conditions for human corneal endothelial cells. In Vitro Cell Dev. Biol. 1989, 25, 1065-1072.

22. Engelmann, K.; Drexler, D.; Bohnke, M. Transplantation of adult human or porcine corneal endothelial cells onto human recipients in vitro. Part I: Cell culturing and transplantation procedure. Cornea 1999, 18, 199-206.

23. Bohnke, M.; Eggli, P.; Engelmann, K. Transplantation of cultured adult human or porcine corneal endothelial cells onto human recipients in vitro. Part II: Evaluation in the scanning electron microscope. Cornea 1999, 18, 207-213.

24. Chen, K.H.; Azar, D.; Joyce, N.C. Transplantation of adult human corneal endothelium ex vivo: A morphologic study. Cornea 2001, 20, 731-737. 
25. Amano, S. Transplantation of corneal endothelial cells. Nihon Ganka Gakkai Zasshi 2002, 106, 805-835.

26. Amano, S. Transplantation of cultured human corneal endothelial cells. Cornea 2003, 22, S66-S74.

27. Mimura, T.; Amano, S.; Usui, T.; Araie, M.; Ono, K.; Akihiro, H.; Yokoo, S.; Yamagami, S. Transplantation of corneas reconstructed with cultured adult human corneal endothelial cells in nude rats. Exp. Eye Res. 2004, 79, 231-237.

28. Mimura, T.; Yamagami, S.; Yokoo, S.; Usui, T.; Tanaka, K.; Hattori, S.; Irie, S.; Miyata, K.; Araie, M.; Amano, S. Cultured human corneal endothelial cell transplantation with a collagen sheet in a rabbit model. Invest. Ophthalmol. Vis. Sci. 2004, 45, 2992-2997.

29. Ishino, Y.; Sano, Y.; Nakamura, T.; Connon, C.J.; Rigby, H.; Fullwood, N.J.; Kinoshita, S. Amniotic membrane as a carrier for cultivated human corneal endothelial cell transplantation. Invest. Ophthalmol. Vis. Sci. 2004, 45, 800-806.

30. Honda, N.; Mimura, T.; Usui, T.; Amano, S. Descemet stripping automated endothelial keratoplasty using cultured corneal endothelial cells in a rabbit model. Arch. Ophthalmol. 2009, 127, 1321-1326.

31. Choi, J.S.; Williams, J.K.; Greven, M.; Walter, K.A.; Laber, P.W.; Khang, G.; Soker, S. Bioengineering endothelialized neo-corneas using donor-derived corneal endothelial cells and decellularized corneal stroma. Biomaterials 2010, 31, 6738-6745.

32. Lai, J.Y.; Chen, K.H.; Hsiue, G.H. Tissue-engineered human corneal endothelial cell sheet transplantation in a rabbit model using functional biomaterials. Transplantation 2007, 84, 1222-1232.

33. Watanabe, R.; Hayashi, R.; Kimura, Y.; Tanaka, Y.; Kageyama, T.; Hara, S.; Tabata, Y.; Nishida, $\mathrm{K}$. A novel gelatin hydrogel carrier sheet for corneal endothelial transplantation. Tissue Eng. Part A 2011, 17, 2213-2219.

34. Liang, Y.; Liu, W.; Han, B.; Yang, C.; Ma, Q.; Zhao, W.; Rong, M.; Li, H. Fabrication and characters of a corneal endothelial cells scaffold based on chitosan. J. Mater. Sci. Mater. Med. 2011, 22, 175-183.

35. Yue, B.Y.; Sugar, J.; Gilboy, J.E.; Elvart, J.L. Growth of human corneal endothelial cells in culture. Invest. Ophthalmol. Vis. Sci. 1989, 30, 248-253.

36. Miyata, K.; Drake, J.; Osakabe, Y.; Hosokawa, Y.; Hwang, D.; Soya, K.; Oshika, T.; Amano, S. Effect of donor age on morphologic variation of cultured human corneal endothelial cells. Cornea 2001, 20, 59-63.

37. Engelmann, K.; Bohnke, M.; Friedl, P. Isolation and long-term cultivation of human corneal endothelial cells. Invest. Ophthalmol. Vis. Sci. 1988, 29, 1656-1662.

38. Yamaguchi, M.; Ebihara, N.; Shima, N.; Kimoto, M.; Funaki, T.; Yokoo, S.; Murakami, A.; Yamagami, S. Adhesion, migration, and proliferation of cultured human corneal endothelial cells by laminin-5. Invest. Ophthalmol. Vis. Sci. 2011, 52, 679-684.

39. Blake, D.A.; Yu, H.; Young, D.L.; Caldwell, D.R. Matrix stimulates the proliferation of human corneal endothelial cells in culture. Invest. Ophthalmol. Vis. Sci. 1997, 38, 1119-1129.

40. Joyce, N.C.; Zhu, C.C. Human corneal endothelial cell proliferation: Potential for use in regenerative medicine. Cornea 2004, 23, S8-S19. 
41. Engelmann, K.; Friedl, P. Growth of human corneal endothelial cells in a serum-reduced medium. Cornea 1995, 14, 62-70.

42. Samples, J.R.; Binder, P.S.; Nayak, S.K. Propagation of human corneal endothelium in vitro effect of growth factors. Exp. Eye Res. 1991, 52, 121-128.

43. Schultz, G.; Cipolla, L.; Whitehouse, A.; Eiferman, R.; Woost, P.; Jumblatt, M. Growth factors and corneal endothelial cells: Iii. Stimulation of adult human corneal endothelial cell mitosis in vitro by defined mitogenic agents. Cornea 1992, 11, 20-27.

44. Shima, N.; Kimoto, M.; Yamaguchi, M.; Yamagami, S. Increased proliferation and replicative lifespan of isolated human corneal endothelial cells with 1-ascorbic acid 2-phosphate. Invest. Ophthalmol. Vis. Sci. 2011, 52, 8711-8717.

45. Joyce, N.C.; Zhu, C.C.; Harris, D.L. Relationship among oxidative stress, DNA damage, and proliferative capacity in human corneal endothelium. Invest. Ophthalmol. Vis. Sci. 2009, 50, 2116-2122.

46. Chen, Q.; Fischer, A.; Reagan, J.D.; Yan, L.J.; Ames, B.N. Oxidative DNA damage and senescence of human diploid fibroblast cells. Proc. Natl. Acad. Sci. USA. 1995, 92, 4337-4341.

47. Miyashita, H.; Higa, K.; Kato, N.; Kawakita, T.; Yoshida, S.; Tsubota, K.; Shimmura, S. Hypoxia enhances the expansion of human limbal epithelial progenitor cells in vitro. Invest. Ophthalmol. Vis. Sci. 2007, 48, 3586-3593.

48. Hansen, J.M.; Klass, M.; Harris, C.; Csete, M. A reducing redox environment promotes C2C12 myogenesis: Implications for regeneration in aged muscle. Cell Biol. Int. 2007, 31, 546-553.

49. Lees, S.J.; Childs, T.E.; Booth, F.W. p21(Cip1) expression is increased in ambient oxygen, compared to estimated physiological (5\%) levels in rat muscle precursor cell culture. Cell Prolif. 2008, 41, 193-207.

50. Mergler, S.; Valtink, M.; Coulson-Thomas, V.J.; Lindemann, D.; Reinach, P.S.; Engelmann, K.; Pleyer, U. TRPV channels mediate temperature-sensing in human corneal endothelial cells. Exp. Eye Res. 2010, 90, 758-770.

51. Mergler, S.; Pleyer, U. Physiology of the human corneal endothelium--new insights from electrophysiological investigations. Klin. Monbl. Augenheilkd. 2011, 228, 520-524.

52. Peh, G.S.L.; Toh, K.P.; Wu, F.Y.; Tan, D.T.; Mehta, J.S. Cultivation of human corneal endothelial cells isolated from paired donor corneas. PLOS ONE 2011, 6, e28310:1-e28310:10.

53. Jackel, T.; Knels, L.; Valtink, M.; Funk, R.H.; Engelmann, K. Serum-free corneal organ culture medium (SFM) but not conventional minimal essential organ culture medium (MEM) protects human corneal endothelial cells from apoptotic and necrotic cell death. Br. J. Ophthalmol. 2011, 95, 123-130.

54. Zhu, C.; Joyce, N.C. Proliferative response of corneal endothelial cells from young and older donors. Invest. Ophthalmol. Vis. Sci. 2004, 45, 1743-1751.

55. Enomoto, K.; Mimura, T.; Harris, D.L.; Joyce, N.C. Age differences in cyclin-dependent kinase inhibitor expression and $\mathrm{rb}$ hyperphosphorylation in human corneal endothelial cells. Invest. Ophthalmol. Vis. Sci. 2006, 47, 4330-4340.

56. Gospodarowicz, D.; Greenburg, G.; Alvarado, J. Transplantation of cultured bovine corneal endothelial cells to species with nonregenerative endothelium. The cat as an experimental model. Arch. Ophthalmol. 1979, 97, 2163-2169. 
57. Gospodarowicz, D.; Greenburg, G.; Alvarado, J. Transplantation of cultured bovine corneal endothelial cells to rabbit cornea: Clinical implications for human studies. Proc. Natl. Acad. Sci. USA 1979, 76, 464-468.

58. Gospodarowicz, D.; Greenburg, G. The coating of bovine and rabbit corneas denuded of their endothelium with bovine corneal endothelial cells. Exp. Eye Res. 1979, 28, 249-265.

59. Jumblatt, M.M.; Maurice, D.M.; McCulley, J.P. Transplantation of tissue-cultured corneal endothelium. Invest. Ophthalmol. Vis. Sci. 1978, 17, 1135-1141.

60. Lange, T.M.; Wood, T.O.; McLaughlin, B.J. Corneal endothelial cell transplantation using descemet's membrane as a carrier. J. Cataract Refract. Surg. 1993, 19, 232-235.

61. Joo, C.K.; Green, W.R.; Pepose, J.S.; Fleming, T.P. Repopulation of denuded murine descemet's membrane with life-extended murine corneal endothelial cells as a model for corneal cell transplantation. Graefes Arch. Clin. Exp. Ophthalmol. 2000, 238, 174-180.

62. McCulley, J.P.; Maurice, D.M.; Schwartz, B.D. Corneal endothelial transplantation. Ophthalmology 1980, 87, 194-201.

63. Jumblatt, M.M.; Maurice, D.M.; Schwartz, B.D. A gelatin membrane substrate for the transplantation of tissue cultured cells. Transplantation 1980, 29, 498-499.

64. Stenzel, K.H.; Dunn, M.W.; Rubin, A.L.; Miyata, T. Collagen gels: Design for a vitreous replace-ment. Science 1969, 164, 1282-1283.

65. Hattori, S.; Adachi, E.; Ebihara, T.; Shirai, T.; Someki, I.; Irie, S. Alkali-treated collagen retained the triple helical conformation and the ligand activity for the cell adhesion via alpha2beta1 integrin. J. Biochem. 1999, 125, 676-684.

66. Sumide, T.; Nishida, K.; Yamato, M.; Ide, T.; Hayashida, Y.; Watanabe, K.; Yang, J.; Kohno, C.; Kikuchi, A.; Maeda, N.; et al. Functional human corneal endothelial cell sheets harvested from temperature-responsive culture surfaces. FASEB J. 2006, 20, 392-394.

67. Brown, S.I.; Hedbys, B.O. The effect of ouabain on the hydration of the cornea. Invest. Ophthalmol. 1965, 4, 216-221.

68. Hodson, S. Evidence for a bicarbonate-dependent sodium pump in corneal endothelium. Exp. Eye Res. 1971, 11, 20-29.

69. Huff, J.W.; Green, K. Demonstration of active sodium transport across the isolated rabbit corneal endothelium. Curr. Eye Res. 1981, 1, 113-114.

70. Fischbarg, J.; Hernandez, J.; Liebovitch, L.S.; Koniarek, J.P. The mechanism of fluid and electrolyte transport across corneal endothelium: Critical revision and update of a model. Curr. Eye Res. 1985, 4, 351-360.

71. Hodson, S.; Wigham, C. The permeability of rabbit and human corneal endothelium. J. Physiol. 1983, 342, 409-419.

72. Wigham, C.; Hodson, S. The effect of bicarbonate ion concentration on trans-endothelial short circuit current in ox corneas. Curr. Eye Res. 1981, 1, 37-41.

73. Wigham, C.G.; Turner, H.C.; Swan, J.; Hodson, S.A. Modulation of corneal endothelial hydration control mechanisms by Rolipram. Pflugers Arch. 2000, 440, 866-870.

74. Koizumi, N.; Sakamoto, Y.; Okumura, N.; Okahara, N.; Tsuchiya, H.; Torii, R.; Cooper, L.J.; Ban, Y.; Tanioka, H.; Kinoshita, S. Cultivated corneal endothelial cell sheet transplantation in a primate model. Invest. Ophthalmol. Vis. Sci. 2007, 48, 4519-4526. 
75. Koizumi, N.; Sakamoto, Y.; Okumura, N.; Tsuchiya, H.; Torii, R.; Cooper, L.J.; Ban, Y.; Tanioka, H.; Kinoshita, S. Cultivated corneal endothelial transplantation in a primate: Possible future clinical application in corneal endothelial regenerative medicine. Cornea 2008, 27, S48-S55.

76. Horan, P.K.; Melnicoff, M.J.; Jensen, B.D.; Slezak, S.E. Fluorescent cell labeling for in vivo and in vitro cell tracking. Methods Cell Biol. 1990, 33, 469-490.

77. Mimura, T.; Yamagami, S.; Yokoo, S.; Araie, M.; Amano, S. Comparison of rabbit corneal endothelial cell precursors in the central and peripheral cornea. Invest. Ophthalmol. Vis. Sci. 2005, 46, 3645-3648.

78. Yamagami, S.; Yokoo, S.; Mimura, T.; Takato, T.; Araie, M.; Amano, S. Distribution of precursors in human corneal stromal cells and endothelial cells. Ophthalmology 2007, 114, 433-439.

(C) 2012 by the authors; licensee MDPI, Basel, Switzerland. This article is an open access article distributed under the terms and conditions of the Creative Commons Attribution license (http://creativecommons.org/licenses/by/3.0/). 